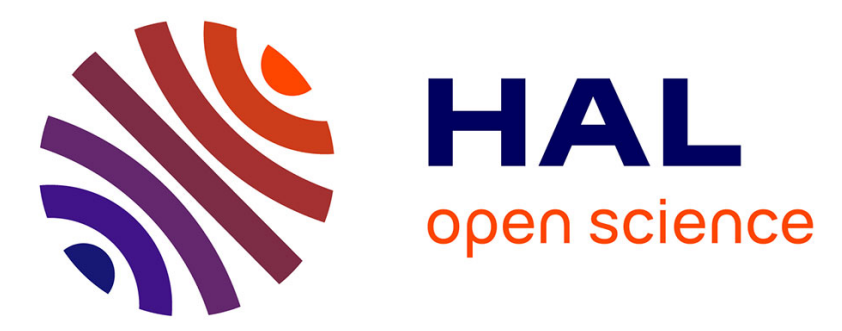

\title{
An N-terminally truncated Smad2 protein can partially compensate for loss of full-length Smad2
}

Debipriya Das, Rebecca A Randall, Caroline S Hill

\section{To cite this version:}

Debipriya Das, Rebecca A Randall, Caroline S Hill. An N-terminally truncated Smad2 protein can partially compensate for loss of full-length Smad2. Biochemical Journal, 2008, 417 (1), pp.205-212. 10.1042/BJ20080014 . hal-00478944

\section{HAL Id: hal-00478944 \\ https://hal.science/hal-00478944}

Submitted on 30 Apr 2010

HAL is a multi-disciplinary open access archive for the deposit and dissemination of scientific research documents, whether they are published or not. The documents may come from teaching and research institutions in France or abroad, or from public or private research centers.
L'archive ouverte pluridisciplinaire HAL, est destinée au dépôt et à la diffusion de documents scientifiques de niveau recherche, publiés ou non, émanant des établissements d'enseignement et de recherche français ou étrangers, des laboratoires publics ou privés. 


\title{
An N-terminally truncated Smad2 protein can partially compensate for loss of full-length Smad2
}

\author{
Debipriya Das ${ }^{1}$, Rebecca A. Randall ${ }^{1}$ and Caroline S. Hill ${ }^{2}$
}

Laboratory of Developmental Signalling, Cancer Research UK London Research Institute, 44 Lincoln's Inn Fields, London WC2A 3PX, UK.

${ }^{1}$ These authors contributed equally to this work

${ }^{2}$ To whom correspondence should be addressed, at Laboratory of Developmental Signalling, Cancer Research UK London Research Institute, 44 Lincoln's Inn Fields, London WC2A 3PX, UK (email caroline.hill@ cancer.org.uk)

\section{Running head: Function of N-terminally truncated Smad2}

Key words: Smad2/TGF- $\beta$ signalling/transcription

Abbreviations used: ARE, Activin-responsive element; DE, distal element; MEF, mouse embryo fibroblast; $\mathrm{MH}$, Mad homology; TGF- $\beta$, transforming growth factor $\beta$. 


\begin{abstract}
TGF- $\beta$ superfamily signalling is critical both for early embryonic development and later for tissue homeostasis in adult organisms. The use of gene disruption techniques in mice has been essential to understand the functional roles of components of the pathways downstream of TGF- $\beta$ superfamily ligands, in particular the receptors and the Smads that transduce the signals from the plasma membrane to the nucleus. Smad 2 functions downstream of TGF- $\beta$, Activin and Nodal, and a number of Smad 2 mutant mice have been generated by different laboratories. Although in all cases these Smad2-deficient mice were embryonic lethal, those created by deletion of the first coding exon survived longer than those generated by replacing part of the Mad homology (MH) 1 domain or deleting all or part of the MH2 domain. Moreover, they displayed a less severe phenotype, as they were capable of transiently inducing mesoderm. Here we show that embryonic fibroblasts taken from the Smad 2 mutant mice created by deletion of the first coding exon express a small amount of an $\mathrm{N}$ terminally truncated Smad2 protein. We show this protein results from internal initiation at methionine 241 and encodes the entire $\mathrm{MH} 2$ domain with the C-terminal part of the linker. We demonstrate that this protein is incorporated into Smad heteromeric complexes, can interact with DNA-binding transcription factors, and thereby mediate TGF- $\beta$-induced transcriptional activation from a number of TGF- $\beta$ responsive elements. We propose that this functional truncated Smad2 protein can partially compensate for the loss of full-length Smad2, thereby providing an explanation for the differing phenotypes of Smad2 mutant mice.
\end{abstract}




\section{INTRODUCTION}

Ligands of the TGF- $\beta$ superfamily have a wide variety of functional roles including embryonic patterning and organogenesis, wound healing, tissue homeostasis, and cell migration, proliferation and differentiation. The effects that the TGF- $\beta$ superfamily ligands exert depend on the cellular context; the cell type, the age of the cell, and the competence of the cell to respond to signal [1]. Additionally strength and duration of signal have important roles in the specificity of the biological consequences of this signalling pathway [2]. Members of this superfamily of ligands signal to the nucleus via complexes of activated Smads. These complexes are composed of phosphorylated receptor-regulated Smads (R-Smads), specifically Smad2 and Smad3 in response to TGF- $\beta$ /Activin/Nodal signalling, in combination with the common mediator Smad (Co-Smad), Smad4 [3].

Sequence alignment reveals that the $\mathrm{R}$ - and Co-Smad proteins have two highlyconserved domains, the N- and C-terminal Mad Homology (MH) 1 and 2 domains, which are separated by a less well-conserved proline-rich linker. The MH1 domain is responsible for the auto-inhibition of the MH2 domain in the basal unphosphorylated state, and additionally, in the case of Smad3 and Smad4 but not Smad2, has some weak intrinsic DNA-binding activity. In contrast, the $\mathrm{MH} 2$ domain is commonly considered to be the 'effector' domain of the Smad, mediating multiple proteinprotein interactions, including those with other Smads, and with the receptors, transcription factor partners, coactivators and corepressors [3].

Owing to their poor affinity for DNA, Smad complexes are primarily recruited to TGF- $\beta$-responsive promoter elements via interactions with site-specific transcription factors. During the development of the early Xenopus embryo, Smad 2 interacts with a number of transcription factors, such as those of the Mix family, namely Mixer, Milk and Bix3 [4, 5], and of the Fast/FoxH1 family, XFoxH1a and XFoxH1b [6, 7], resulting in transcriptional activation of, for example, the goosecoid gene via the DE (distal element), and the Mix.2 gene via the ARE (activin-responsive element), respectively. Here the Smad-transcription factor interaction is mediated by the highly conserved proline-rich Smad interaction motif (SIM) present in the C-termini of these transcription factors, which binds to a hydrophobic pocket in the Smad2 MH2 domain [5]. Additionally, the FoxH1s contain a Fast/FoxH1 motif (FM), which allows them to specifically interact with phosphorylated Smad2-containing activated Smad complexes [8].

Targeted gene disruption in mice has hugely advanced our understanding of how and when the Smads function. Unlike Smad3 mutant mice that are viable and survive to term [9-11], Smad2-deficient mice that were generated by replacing part of the MH1 domain or inserting a LacZ reporter in the MH2 domain [12], or by deleting part of the $\mathrm{MH} 2$ domain [13] are embryonic lethal (E7.5-8.5) and exhibit severe gastrulation defects. These mice fail to form an egg cylinder and lack all mesoderm, as evidenced by the complete lack of Brachyury expression [12, 13]. A proportion of Smad2 heterozygous embryos also exhibit gastrulation defects, and lack mandibles and eyes later in development, indicating that signalling through Smad2 may function in a dose-dependent fashion [12, 13], confirming previous studies in Xenopus [14, 15]. Interestingly, Smad2 mutant mice generated by two further laboratories by disruption of the first coding exon displayed a transient induction of mesoderm [16, 17], suggesting that Smad2 was dispensible for mesoderm induction. We previously demonstrated that mouse embryonic fibroblasts (MEFs) taken from such homozygous 
mice $[16,18]$ express a low level of truncated Smad2 protein that is phosphorylated in response to TGF- $\beta$ [8]. Since the phenotype of the mice expressing this N-terminally truncated Smad2 $[16,17]$ was less severe than that of the other Smad2 mutant mice $[12,13]$, we wanted to fully characterise this truncated protein to determine if it is functional. Here we show that this truncated Smad2 protein results from internal initiation from methionine 241 and encodes the entire MH2 domain as well as the Cterminal region of the linker. We demonstrate that, as for wild-type Smad2, this protein forms heteromeric complexes with Smad4 in response to TGF- $\beta$ that are able to mediate ligand-induced transcriptional activation. We go on to show that truncated Smad2 is incorporated into stable DNA-binding complexes with FoxH1a/b and Smad4 or FoxH1a/b, Smad3 and Smad4. Therefore, the truncated Smad2 protein expressed in these MEFs is functional and we propose that it could partially compensate for loss of full-length Smad2 in the Smad2-deficient mice, thereby accounting for the observed differences in phenotype of the previously described Smad2 mutant mice. 


\section{MATERIALS AND METHODS \\ Plasmids:}

The following plasmids have been described: pEF-HA Mixer [8]; XFoxH1a and

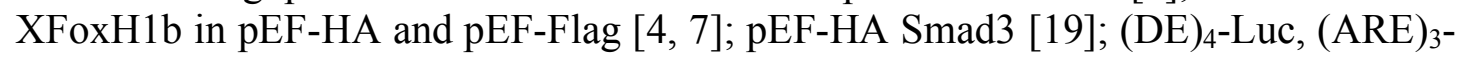
Luc and pEF-LacZ [20]; CAGA $_{12}-$ Luc [21]. pEF and pEF-HA Smad2(241-467) were constructed by PCR. Oligos were designed to amplify the region by PCR of mouse Smad2 corresponding to amino acids 241 to 467 and the resulting sequence was cloned into $\mathrm{pEF}$-plink [22] and pEF-HA. The M241A point mutation was made in the context of pEF-Smad2(241-467) using PCR. All constructs were verified by sequencing.

\section{Transfections, reporter assays and RT-PCR:}

Maintenance of NIH-3T3 cells, transfection and reporter assays were as described [20]. HEK-293T cells and MEFs (wild-type and S2 KO) were cultured in Dulbecco's modified Eagle's medium (DMEM) $/ 10 \%$ fetal bovine serum and were transfected using jetPEI (Polyplus-transfection) or Lipofectamine 2000 in combination with Plus Reagent (Invitrogen), respectively, both according to the manufacturers' instructions. siRNA transfections in S2 KO MEFs were performed in 6-well plates. Cells were seeded at $1 \times 10^{5}$ cells per well on the day prior to transfection. Each well was transfected with $8 \mathrm{nM}$ final concentration of siRNA using Interferin (Polyplustransfection). Cells were incubated for $72 \mathrm{hrs}$ and then treated with TGF- $\beta$. When cells were treated with both siRNA and plasmid DNA, cells were seeded at $2.5 \times 10^{4}$ cells per well in 12-well plates. Cells were transfected first with siRNA for 48 hours, and then transfected for an additional 24 hours with plasmid DNA prior to being treated \pm TGF- $\beta$. siRNAs were purchased from Dharmacon and had the following catalogue numbers: Smad2 (D-040707-04), Smad3 (M-040706-00). TGF- $\beta 1$ (Peprotech Ltd) was used at $2 \mathrm{ng} / \mathrm{ml}$, and Activin at $40 \mathrm{ng} / \mathrm{ml}$ (R\&D Systems), and inductions were for 1 hour, except in reporter assays when cells were treated with ligand for 8 hours. In the case of HEK-293Ts, cells were treated overnight with 10 $\mu \mathrm{M}$ SBI (SB-431542; Tocris) to inhibit autocrine TGF- $\beta$ /Activin/Nodal signalling prior to washing the cells with fresh medium and induction with Activin. We use Activin in this case instead of TGF- $\beta$ as HEK-293T cells respond better to Activin [23]. RT-PCR was performed as previously described [24]. Primers used have the following sequences: GAPDH-Fwd, 5'-ACCACAGTCCATGCCATCAC-3'; GAPDHRev, 5'-TCCACCACCCTGTTGCTGTA-3'; mSmad2-Fwd, 5'GCTTAGGCTTGCTCTCCAAC-3'; mSmad2-Rev, 5'-ATTCTTATGGTGCACATT CGG-3'.

\section{Immunoprecipitation, Western blotting and bandshift assays}

Nuclear, cytoplasmic and whole-cell extracts were prepared as previously described $[7,25]$. Immunoprecipitations were carried out as previously described [20]. Bandshifts probes corresponding to the ARE were synthesised as described [19], and bandshifts were performed as described [4] except that $50 \mu \mathrm{g}$ whole-cell extract was used per lane. Antibodies used in Western blots, immunoprecipitations and bandshifts were anti-phospho-Smad2 (Cell Signalling Technology); anti-Smad4, (B8; Santa Cruz); anti-Flag, M2 (Sigma); anti-Smad2/3 and anti-Grb2 (BD Biosciences); antiSmad3 (Zymed); anti-PARP, anti-HA and anti-HA-HRP (Roche). 


\section{RESULTS \\ Smad2-null mouse embryonic fibroblasts express a truncated form of Smad2 that is nuclear and can be phosphorylated in response to TGF- $\beta$}

In response to TGF- $\beta$, Smad 2 is phosphorylated on the last two serines of the Cterminal SSXS motif and, in complex with Smad4, accumulates in the nucleus where it regulates gene expression. The truncated Smad2 protein expressed by the Smad2null MEFs (hereafter called S2 KO MEFs [18]) is phosphorylated when cells are stimulated with TGF- $\beta$ [8]. In order to test whether this protein acts like full-length Smad2, we compared its behaviour to Smad2 protein from wild-type MEFs in a number of assays. Nuclear and cytoplasmic extracts were prepared from wild-type and S2 KO MEFs cultured in the presence or absence of TGF- $\beta$ and were Western blotted for the phosphorylated form of Smad2. As expected, wild-type MEFs express Smad2, and this is phosphorylated and accumulates in the nucleus upon TGF- $\beta$ addition (Figure 1). As previously demonstrated [8], the S2 KO MEFs express a small quantity of truncated Smad 2 protein that can be phosphorylated upon TGF- $\beta$ addition. This protein was nuclear when the cells were stimulated with ligand (Figure 1). As antibodies specific for unphosphorylated Smad2 cannot recognise this truncated Smad2 protein it is not possible to determine its cellular localisation in the absence of signal. Antibodies against PARP and Grb2 were used as loading controls for nuclear and cytoplasmic extracts, respectively.

\section{Internal initiation of translation at methionine 241 gives rise to the truncated Smad2 protein}

We next determined what amino acid residues the truncated Smad 2 corresponded to. It was previously shown that mice deleted in the first coding exon of Smad2 expressed an RNA transcript 300 base pairs shorter than wild type [26]. This transcript arises by splicing around the PGKneomycin cassette replacing the first coding exon. There are only three in-frame methionines from which the truncated Smad2 protein could start: M241, M327 and M411. Moreover, we know it contains the extreme C-terminus of $\mathrm{Smad} 2$ as it is phosphorylated in response to TGF- $\beta$. From its size, the truncated Smad2 protein, which runs at approximately $28 \mathrm{kDa}$, would be predicted to start at the first internal in-frame methionine, Met241, and would therefore encode the entire $\mathrm{MH} 2$ domain along with the most C-terminal 33 amino acids of the linker (Figure 2A). To test this, a version of mouse Smad2 beginning at Met241, Smad2(241-467), was constructed. This plasmid was transfected into NIH$3 \mathrm{~T} 3$ cells and whole-cell extracts from cells treated with or without TGF- $\beta$ were compared with extracts from wild-type and S2 KO MEFs by Western blot using the antibody against phosphorylated Smad2. The endogenous truncated Smad2 protein migrated on SDS-PAGE identically to the transfected Smad2 construct (Figure 2B). Full-length endogenous Smad2 is present and is phosphorylated upon TGF- $\beta$ stimulation in both the NIH-3T3s and the wild-type MEFs. To confirm that Met241 was indeed the initiation codon, we made a construct in which it was mutated to alanine. This plasmid was transfected, along with wild-type Smad2(241-467) expression plasmid into human HEK-293T cells, so as to be able to distinguish mouse and human Smad2 transcripts. Mutation of Met241 to alanine resulted in complete loss of the truncated Smad2 protein (Figure 2C) despite significant mRNA levels being detected (Figure 2D). This confirms that the protein expressed in S2 KO MEFs is the result of internal initiation at Met241. 


\section{Truncated Smad2 forms a heteromeric complex with Smad4 in response to TGF- $\beta$}

Upon TGF- $\beta$ stimulation, Smad oligomerisation occurs in order to form transcriptionally active R-Smad-Smad4 heterodimers and heterotrimers [19, 27-30]. These complexes are the result of extensive protein-protein interactions between the MH2 domains of the Smads, and are stabilised by binding of the phosphorylated Cterminus of the R-Smad with the L3 loop/B8 $\beta$-strand of the adjacent monomer [27]. Since the Smad2 protein expressed by the S2 KO MEFs is N-terminally truncated and therefore has an intact $\mathrm{MH} 2$ domain, we wanted to determine whether it could form heteromeric complexes with Smad4. Whole-cell extracts from uninduced or TGF- $\beta$ induced wild-type and S2 KO MEFs were immunoprecipitated with the anti-Smad4 antibody and then Western blotted to detect endogenous phosphorylated Smad2. Smad4 immunoprecipitated full-length phospho-Smad2 from wild-type MEFs, and truncated phospho-Smad2 from S2 KO MEFs (Figure 3). Thus, internal initiation from Met241 produces a Smad2 protein that is appropriately folded and capable of forming heteromeric complexes with Smad4.

\section{TGF- $\beta$-induced transcriptional activation is supported by truncated Smad2}

Smad2 cannot bind DNA directly and thus forms transcriptionally active complexes through its interaction with a number of different transcription factors. The best characterised Smad2-interacting transcription factors are found in the early Xenopus embryo. Here, Smad2-Smad4 complexes interact with paired-like homeodomain transcription factors of the Mix family, such as Mixer, Milk and Bix3, in order to be recruited to the distal element (DE) of the goosecoid promoter, and with the forkhead/winged-helix transcription factors FoxH1a and FoxH1b at the Mix.2 ARE [4-7]. Since the Smad complex interacts with these transcription factors through the Smad2 MH2 domain [4], and we have demonstrated that the truncated Smad2 protein can form Smad2-Smad4 complexes (Figure 3), it is conceivable that this protein can also interact with its transcription factor partners and thereby mediate TGF- $\beta$-induced transcriptional activation. Indeed, it has been demonstrated in in vitro transcription assays from chromatinised templates that this portion of Smad2 has transcriptional activity [31]. In order to test whether the truncated Smad2 protein can form active Smad-transcription factor complexes and is therefore functional, wild-type and S2 KO MEFs were transfected with Mixer and the (DE) $)_{4}$-Luc reporter, or with FoxH1a or FoxH1b and the (ARE) $)_{3}$-Luc reporter construct, and then treated with or without TGF- $\beta$. Additionally, the two cell lines were transfected with the Smad3-dependent reporter $\mathrm{CAGA}_{12}$-Luc, which acted as a TGF- $\beta$-responsive, but Smad2-independent, control. The results indicate that there is no significant difference in the ability of fulllength or truncated Smad 2 to mediate TGF- $\beta$-induced transcriptional activation. In the wild-type MEFs, treatment with TGF- $\beta$ resulted in an average 3.1-fold induction of (DE) $_{4}$-Luc when Mixer was also transfected (Figure 4A and Table 1) and, in the same way, this reporter was induced 3.8-fold in the S2 KO MEFs. Similarly, (ARE) ${ }_{3}$-Luc was activated comparably in both cell types when FoxH1a/FoxH1b and TGF- $\beta$ were present. As expected for a Smad3-dependent reporter, induction of the CAGA 12 -Luc reporter was not significantly different in the S2 KO MEFs when compared to the wild-type cells, being induced 12.3-fold and 10.1-fold, respectively (Figure 4A and Table 1).

Since the S2 KO MEFs contain levels of Smad3 comparable with those in wild-type MEFs, it remained a possibility that Smad3 could be mediating the TGF- $\beta$-induced 

overexpressed, the lower two complexes of the native trimer were enhanced at the expense of the upper complex as would be expected if they contain the truncated Smad2, and these complexes shifted with the addition of the anti-HA antibody (Figure 5B, compare lanes 8 and 12). In contrast, exogenous HA-tagged Smad3 increased the amount of the top two complexes, supporting the theory that these contain Smad3Smad4 and truncated Smad2-Smad3-Smad4 heterotrimers, respectively. These complexes were shifted with a Smad3 antibody and also with an anti-HA antibody, (Figure 5B, compare lanes 14, 16 and 18). Extracts were Western blotted to check levels of expression of the HA-tagged Smads (Figure 5C).

Thus, taking all our results together we conclude that truncated Smad2 can form stable complexes with either Smad4 and FoxH1 or with Smad3 


\section{DISCUSSION}

Here we show that mouse embryonic fibroblasts lacking expression of full-length Smad2 [18] express a small amount of a truncated form of Smad2 that starts at Met241 and encodes the entire MH2 domain and the most C-terminal end of the linker. This protein is functional in terms of its ability to be phosphorylated by the receptor, to form complexes with transcription factors and other Smads, and consequently it mediates ligand-induced transcriptional activation of a number of TGF- $\beta$-responsive reporter constructs. In fact, further N-terminal deletion of Smad 2 to residue 245 results in loss of the ability to be phosphorylated by the receptor [8], indicating that this truncated Smad2 is the minimal fragment that can be activated by TGF- $\beta$. The mice from which these embryonic fibroblasts were taken were created by disruption of the first coding exon of Smad2 [16]. Mice created using this strategy $[16,17]$ showed a less severe phenotype than Smad2-null mice generated differently by two further labs [12, 13], displaying a transient induction of mesoderm as well as surviving for an additional day. We propose that this is the result of the incomplete loss of all functional Smad2 protein, and that there is sufficient Smad2 activity in the form of this N-terminally truncated Smad 2 to account for the less severe phenotype.

Studies in Xenopus demonstrate that Activin, Nodal and Smad2 all act in a dosedependent manner to induce mesoderm [14, 15, 32, 33], the result of different transcriptional activation thresholds of specific Smad2-responsive genes. Since the genetic response of a cell to TGF- $\beta$ superfamily ligands is a consequence of the strength and duration of the signal, and this itself is a function of the concentration of active Smad complexes in the nucleus, decreased cellular Smad levels would be expected to considerably affect TGF- $\beta$ /Activin/Nodal-responsive transcriptional regulation.

A previous study investigated the expression of a number of TGF- $\beta$-dependent genes in Smad2- and Smad3-deficient fibroblasts [18]. Here the authors identified a number of Smad3-dependent genes, including $c$-fos, Smad7 and TGF- $\beta 1$, whereas loss of Smad2 alone had no significant effect on the expression of all but one of the genes analysed $(M M P-2)$. However, the Smad2-null MEFs used in this study were the same ones as those described here and therefore express truncated, functional Smad2 protein. The small number of Smad2-dependent target genes identified in this study is thus expected to be artificially low. It is therefore also likely that a number of the 'Smad3-dependent' genes identified are also additionally regulated by Smad2, and that these two R-Smads have considerable overlapping but non-redundant roles in TGF- $\beta$-mediated gene expression.

The ability of Smad3 to interact with FoxH1 family members and thus compensate for loss of Smad2 has been previously investigated. Experiments using overexpressed or recombinant purified Smad3 have supported the proposed interaction between these proteins [34-37]. However, unless Smad3 is overexpressed, an ARF1 complex formed in $\mathrm{HaCaT}$ cells does not contain Smad3 when assayed by bandshift [8]. This suggests that Smad2 is preferentially recruited into ARF complexes over Smad3. FoxH1a and FoxH1b are thought to interact with a Smad heterotrimer composed of two Smad2s and one Smad4 through their two Smad-interaction motifs; the SIM contacts one Smad2 subunit, and the FM contacts the second [8]. The FM allows FoxH1a/FoxH1b to discriminate between Smad2/Smad4 heterotrimeric and Smad3/Smad4 heterodimeric complexes. This has been attributed to the fact that the FM recognises the R-Smad-R-Smad interface in the Smad heteromer and, since the Smad3/Smad4 
complex is dimeric, at least when bound to the c-Jun Smad binding region [19], it therefore lacks this binding groove. However, in vitro purified activated Smad3 can form heterotrimeric complexes in association with Smad4, with a stoichiometry of two Smad3s and one Smad4 [27, 38, 39].

Here we have demonstrated that when endogenous levels of Smad2 protein are low, as in the wild-type MEFs, or when Smad2 is truncated and expressed at low level, as in the S2 KO MEFs, Smad3 can become incorporated into ARF complexes and mediate ligand-induced activation of the (ARE) $)_{3}$-Luc reporter. In the S2 KO MEFs TGF- $\beta$-induced transcriptional activation is thus likely to be mediated by complexes containing Smad4 and truncated Smad2, either alone or in combination with Smad3. Indeed, our knockdown experiment (Figure 4B) confirms that both truncated Smad2 and Smad3 contribute to transcriptional activation via the ARE. Thus the truncated Smad 2 protein has transcriptional activity and can clearly partially compensate for the loss of full-length Smad2, since the mice that express this protein $[16,17]$ have a less severe phenotype than those generated by methods other than deletion of the first coding exon $[12,13]$. However, it is important to note that since the mice expressing truncated Smad2 still fail to develop normally and make it to term, this truncated Smad 2 cannot fully compensate for the loss of the full-length protein. This could either be the result of the reduced levels of expression of the truncated protein, which mean it is simply not at a high enough threshold to activate certain developmental genes, or might indicate an as yet unidentified role for the MH1 domain of Smad2. This second possibility seems likely in the light of recent work showing that directed expression of Smad2(Dexon3), but not Smad2(full length) can rescue the ability of Smad2-deficient ES cells to contribute to descendants of definitive endoderm in wildtype host embryos [40]. In addition, mice that express exclusively Smad2(Uexon3) develop normally and are viable and fertile. The difference in ability of Smad2(Dexon3) versus Smad2(full length) to rescue the loss of Smad2 suggests a critical function of the Smad2 MH1 domain which lacks exon 3. Since the truncated Smad2 we study here has no MH1 domain it cannot therefore fully rescue Smad2 null embryos. 


\section{ACKNOWLEDGEMENTS}

We would like to thank Liz Robertson and Liz Bikoff and members of the Hill lab for useful discussions, and Laurence Levy for comments on the manuscript. The work was supported by Cancer Research UK. 


\section{REFERENCES}

1 Massague, J. (2000) How cells read TGF- $\beta$ signals. Nat. Rev. Mol. Cell Biol. 1, 169-178

2 Schmierer, B. and Hill, C. S. (2007) TGF $\beta-S M A D$ signal transduction: molecular specificity and functional flexibility. Nat. Rev. Mol. Cell Biol. 8, 970-982

3 Feng, X. H. and Derynck, R. (2005) Specificity and versatility in TGF- $\beta$ signaling through Smads. Annu. Rev. Cell Dev. Biol. 21, 659-693

4 Germain, S., Howell, M., Esslemont, G. M. and Hill, C. S. (2000) Homeodomain and winged-helix transcription factors recruit activated Smads to distinct promoter elements via a common Smad interaction motif. Genes Dev. 14, 435-451

5 Randall, R. A., Germain, S., Inman, G. J., Bates, P. A. and Hill, C. S. (2002) Different Smad2 partners bind a common hydrophobic pocket in Smad2 via a defined proline-rich motif. EMBO J. 21, 145-156

6 Chen, X., Rubock, M. J. and Whitman, M. (1996) A transcriptional partner for MAD proteins in TGF- $\beta$ signalling. Nature. 383, 691-696

7 Howell, M., Inman, G. J. and Hill, C. S. (2002) A novel Xenopus Smadinteracting forkhead transcription factor (XFast-3) cooperates with XFast-1 in regulating gastrulation movements. Development. 129, 2823-2834

8 Randall, R. A., Howell, M., Page, C. S., Daly, A., Bates, P. A. and Hill, C. S. (2004) Recognition of phosphorylated-Smad2-containing complexes by a novel Smad interaction motif. Mol. Cell. Biol. 24, 1106-1121

9 Datto, M. B., Frederick, J. P., Pan, L., Borton, A. J., Zhuang, Y. and Wang, X. F. (1999) Targeted disruption of Smad3 reveals an essential role in transforming growth factor $\beta$-mediated signal transduction. Mol. Cell. Biol. 19, 2495-2504

10 Yang, X., Letterio, J. J., Lechleider, R. J., Chen, L., Hayman, R., Gu, H., Roberts, A. B. and Deng, C. (1999) Targeted disruption of SMAD3 results in impaired mucosal immunity and diminished $\mathrm{T}$ cell responsiveness to TGF- $\beta$. EMBO J. 18, 1280-1291

11 Zhu, Y., Richardson, J. A., Parada, L. F. and Graff, J. M. (1998) Smad3 mutant mice develop metastatic colorectal cancer. Cell. 94, 703-714

12 Nomura, M. and Li, E. (1998) Smad2 role in mesoderm formation, left-right patterning and craniofacial development. Nature. 393, 786-790

13 Weinstein, M., Yang, X., Li, C., Xu, X., Gotay, J. and Deng, C. X. (1998) Failure of egg cylinder elongation and mesoderm induction in mouse embryos lacking the tumor suppressor smad2. Proc. Natl. Acad. Sci. U S A. 95, 9378-9383

14 Baker, J. C. and Harland, R. M. (1996) A novel mesoderm inducer, Madr2, functions in the activin signal transduction pathway. Genes Dev. 10, 1880-1889

15 Graff, J. M., Bansal, A. and Melton, D. A. (1996) Xenopus Mad proteins transduce distinct subsets of signals for the TGF- $\beta$ superfamily. Cell. 85, 479-487

16 Heyer, J., Escalante-Alcalde, D., Lia, M., Boettinger, E., Edelmann, W., Stewart, C. L. and Kucherlapati, R. (1999) Postgastrulation Smad2-deficient embryos show defects in embryo turning and anterior morphogenesis. Proc. Natl. Acad. Sci. U S A. 96, 12595-12600

17 Waldrip, W. R., Bikoff, E. K., Hoodless, P. A., Wrana, J. L. and Robertson, E. J. (1998) Smad2 signaling in extraembryonic tissues determines anterior-posterior polarity of the early mouse embryo. Cell. 92, 797-808

18 Piek, E., Ju, W. J., Heyer, J., Escalanate-Alcalde, D., Stewart, C. L., Weinstein, M., Deng, C., Kucherlapati, R., Böttinger, E. P. and Roberts, A. B. (2001) 
Functional characterization of TGF- $\beta$ signaling in Smad2- and Smad3- deficient fibroblasts. J. Biol. Chem. 276, 19945-19953

19 Inman, G. J. and Hill, C. S. (2002) Stoichiometry of active Smad-transcription factor complexes on DNA. J. Biol. Chem. 277, 51008-51016

20 Pierreux, C. E., Nicolás, F. J. and Hill, C. S. (2000) Transforming growth factor $\beta$-independent shuttling of Smad4 between the cytoplasm and nucleus. Mol. Cell. Biol. 20, 9041-9054

21 Dennler, S., Itoh, S., Vivien, D., ten Dijke, P., Huet, S. and Gauthier, J. M. (1998) Direct binding of Smad3 and Smad4 to critical TGF $\beta$-inducible elements in the promoter of human plasminogen activator inhibitor-type 1 gene. EMBO J. 17, 3091-3100

22 Hill, C. S., Wynne, J. and Treisman, R. (1995) The Rho family GTPases RhoA, Rac1, and CDC42Hs regulate transcriptional activation by SRF. Cell. 81, $1159-1170$

23 Levy, L., Howell, M., Das, D., Harkin, S., Episkopou, V. and Hill, C. S. (2007) Arkadia activates Smad3/Smad4-dependent transcription by triggering signalinduced SnoN degradation. Mol. Cell. Biol. 27, 6068-6083

24 Levy, L. and Hill, C. S. (2005) Smad4 dependency defines two classes of transforming growth factor $\beta$ (TGF- $\beta$ ) target genes and distinguishes TGF- $\beta$-induced epithelial-mesenchymal transition from its antiproliferative and migratory responses. Mol. Cell. Biol. 25, 8108-8125

25 Marais, R., Wynne, J. and Treisman, R. (1993) The SRF accessory protein Elk-1 contains a growth factor-regulated transcriptional activation domain. Cell. 73, 381-393

26 Tremblay, K. D., Hoodless, P. A., Bikoff, E. K. and Robertson, E. J. (2000) Formation of the definitive endoderm in mouse is a Smad2-dependent process. Development. 127, 3079-3090

27 Chacko, B. M., Qin, B., Correia, J. J., Lam, S. S., de Caestecker, M. P. and Lin, K. (2001) The L3 loop and C-terminal phosphorylation jointly define Smad protein trimerization. Nat. Struct. Biol. 8, 248-253

28 Shi, Y., Hata, A., Lo, R. S., Massagué, J. and Pavletich, N. P. (1997) A structural basis for mutational inactivation by the tumour suppressor Smad4. Nature. 388, 87-93

29 Wu, J. W., Fairman, R., Penry, J. and Shi, Y. (2001) Formation of a Stable Heterodimer between Smad2 and Smad4. J Biol Chem. 276, 20688-20694

30 Wu, J. W., Hu, M., Chai, J., Seoane, J., Huse, M., Li, C., Rigotti, D. J., Kyin, S., Muir, T. W., Fairman, R., Massagué, J. and Shi, Y. (2001) Crystal structure of a phosphorylated Smad2. Recognition of phosphoserine by the MH2 domain and insights on Smad function in TGF- $\beta$ signaling. Mol. Cell. 8, 1277-1289

31 Ross, S., Cheung, E., Petrakis, T. G., Howell, M., Kraus, W. L. and Hill, C. S. (2006) Smads orchestrate specific histone modifications and chromatin remodeling to activate transcription. EMBO J. 25, 4490-4502

32 Green, J. B., New, H. V. and Smith, J. C. (1992) Responses of embryonic Xenopus cells to activin and FGF are separated by multiple dose thresholds and correspond to distinct axes of the mesoderm. Cell. 71, 731-739

33 Jones, C. M., Kuehn, M. R., Hogan, B. L. M., Smith, J. C. and Wright, C. V. E. (1995) Nodal-related signals induce axial mesoderm and dorsalize mesoderm during gastrulation. Development. 121, 3651-3662

34 Labbe, E., Silvestri, C., Hoodless, P. A., Wrana, J. L. and Attisano, L. (1998) Smad 2 and Smad 3 positively and negatively regulate TGF $\beta$-dependent transcription through the forkhead DNA-binding protein FAST2. Mol. Cell. 2, 109-120 
35 Nagarajan, R. P., Zhang, J., Li, W. and Chen, Y. (1999) Regulation of Smad7 promoter by direct association with Smad3 and Smad4. J. Biol. Chem. 274, 3341233418

36 Yagi, K., Goto, D., Hamamoto, T., Takenoshita, S., Kato, M. and Miyazono, K. (1999) Alternatively spliced variant of Smad2 lacking exon 3. Comparison with wild-type Smad2 and Smad3. J. Biol. Chem. 274, 703-709

37 Yeo, C. Y., Chen, X. and Whitman, M. (1999) The role of FAST-1 and Smads in transcriptional regulation by activin during early Xenopus embryogenesis. J. Biol. Chem. 274, 26584-26590

38 Correia, J. J., Chacko, B. M., Lam, S. S. and Lin, K. (2001) Sedimentation studies reveal a direct role of phosphorylation in Smad3:Smad4 homo- and heterotrimerization. Biochemistry. 40, 1473-1482

39 Qin, B. Y., Lam, S. S., Correia, J. J. and Lin, K. (2002) Smad3 allostery links TGF- $\beta$ receptor kinase activation to transcriptional control. Genes Dev. 16, 19501963

40 Dunn, N. R., Koonce, C. H., Anderson, D. C., Islam, A., Bikoff, E. K. and Robertson, E. J. (2005) Mice exclusively expressing the short isoform of Smad2 develop normally and are viable and fertile. Genes Dev. 19, 152-163 


\section{LEGENDS}

\section{Figure 1}

Truncated Smad2 is phosphorylated and nuclear in response to TGF- $\beta$ signalling. Cytoplasmic (Cyt) and nuclear (Nuc) extracts were prepared from wild-type and S2 KO MEFs that had been treated with or without TGF- $\beta$ for 1 hour. Extracts were then analysed by Western blot, probing with an anti-phosphorylated Smad2 antibody, along with anti-PARP and anti-Grb2 antibodies that acted as controls for nuclear and cytoplasmic proteins, respectively. The positions of the molecular weight markers are shown on the left of the top panel.

\section{Figure 2}

The truncated Smad2 protein expressed by S2 KO MEFs is the result of an internal initiation at methionine 241. (A) Schematic of Smad2 showing the position of Met241, and the truncated Smad2(241-467) protein. (B) Whole-cell extracts prepared from uninduced or TGF- $\beta$-induced wild-type and S2 KO MEFS, and from NIH-3T3s overexpressing Smad2(241-467), were assayed by Western blotting with the antiphosphorylated Smad2 antibody. (C) HEK-293T cells were transfected with plasmids expressing Smad2(241-467) or the mutant Smad2(M241A-467) or remained untransfected. Cells were then treated with the ALK5 inhibitor SB-431542 to inhibit autocrine signalling (lanes marked -). After 15 hours, the SB-431542 was washed out in half the samples and these were treated with Activin for 1 hour (lanes marked + ). Whole-cell extracts were assayed by Western blot for phospho-Smad2, and Smad2/3 and Grb2 as loading controls. Note that although the 15-hour treatment with SB431542 was sufficient to cause dephosphorylation of full-length Smad2 in the HEK293 cells, it was not sufficient to cause dephosphorylation of the truncated Smad2. (D) Total RNA was isolated from the HEK-293Ts (untransfected), or those overexpressing the wild-type or M241A truncated Smad2 constructs and RT-PCR was performed using primers specific for mouse Smad2, and GAPDH as a control (+RT panels). To ensure plasmid DNA was not being detected, RT-PCR reactions were also performed in the absence of reverse transcriptase (-RT panels).

\section{Figure 3}

Smad4 can form a complex with the truncated Smad2 protein. Whole-cell extracts were prepared from wild-type or S2 KO MEFs that had been incubated with or without TGF- $\beta$ for 1 hour. Extracts were then assayed by immunoprecipitation of complexes with anti-Smad4 antibody followed by Western blotting with antiphosphorylated-Smad2 antibody (top). Western blotting of whole-cell extracts (inputs) with anti-phosphorylated-Smad2 (middle) and anti-Smad4 (bottom) antibodies acted as loading controls. A non-specific background band is marked by an asterisk.

\section{Figure 4}

Truncated Smad 2 can mediate TGF- $\beta$-induced transcriptional activation via the DE and ARE, comparable with wild-type full-length Smad2. (A) Wild-type (top) and S2 KO MEFs (bottom) were transfected with the (DE) 4 -luciferase, (ARE) $)_{3}$-luciferase or $\mathrm{CAGA}_{12}$-luciferase reporters along with plasmids expressing Mixer, FoxH1a or FoxH1b, as indicated. Cells were incubated in the presence or absence of TGF- $\beta$ for 8 hours, and luciferase was quantitated relative to the $\beta$-Gal internal control. Data are from one representative experiment performed in triplicate. Refer to Table 1 for the mean and standard deviation of four independent experiments. (B) S2 KO MEFs were 
transfected with the control non-target siRNA SMARTpool or with an siRNA single duplex targeting mouse Smad2 $(\mathrm{mS} 2)$ or an siRNA SMARTpool targeting mouse Smad3 (mS3), followed by transfection with (ARE) $)_{3}$-Luciferase with or without a plasmid expressing FoxH1b and treatment with or without TGF- $\beta$, as for (A). Data are the mean and standard deviation of one representative experiment performed in triplicate. (C) Western blot to show specificity of knock down of mouse Smad 2 and mouse Smad3 siRNAs used in (B), blotted with anti-Smad2/3, anti-phosphorylated Smad2, and anti-Grb2 as a control.

\section{Figure 5}

The truncated Smad2 protein can form stable complexes on the ARE with Smad3 and Smad4, and either FoxH1a or FoxH1b. (A) Wild-type and S2 KO MEFs were transfected with plasmids expressing Flag-tagged FoxH1a (left panel) or FoxH1b (right panel). Cells were either untreated or treated with TGF- $\beta$ for 1 hour. Whole-cell extracts were then analysed by bandshift using the ARE probe. The ARF1/2 complexes were shifted with the indicated antibodies to show that they contained FoxH1a/FoxH1b, Smad2, Smad3 and Smad4. Asterisks represent the three ARF1/2 complexes formed in the S2 KO MEFs. (B) Whole-cell extracts from wild-type and S2 KO MEFs treated with or without TGF- $\beta$ and transfected with Flag-tagged FoxH1a, either alone or with plasmids expressing HA-tagged Smad2 or Smad3, were assayed by bandshift using the ARE probe. Complexes were incubated with antibodies to demonstrate that the three ARF1 bands (as indicated by asterisks) contained varying heterotrimers of Smad3 and truncated Smad2, with Smad4 and FoxH1a. (C) Western blot of whole-cell extracts from (B) probed with anti-HA-HRP, anti-phosphorylated Smad2 and anti-Grb2 antibodies to show levels of transfected plasmids. Grb2 acts as a loading control. 


\section{Table 1}

\begin{tabular}{|c|c|c|c|c|c|c|}
\hline \multirow{2}{*}{\multicolumn{2}{|c|}{$\begin{array}{l}\text { Reporter }+ \\
\text { transcription factor }\end{array}$}} & \multirow[b]{2}{*}{ TGF- $\beta$} & \multicolumn{2}{|c|}{ Wild-type MEFs } & \multicolumn{2}{|l|}{ S2 KO MEFs } \\
\hline & & & $\begin{array}{l}\text { Average fold } \\
\text { induction } \\
\text { relative to } \\
\text { uninduced }\end{array}$ & $\begin{array}{l} \pm \text { Standard } \\
\text { deviation }\end{array}$ & $\begin{array}{l}\text { Average fold } \\
\text { induction }\end{array}$ & $\begin{array}{l} \pm \text { Standard } \\
\text { deviation }\end{array}$ \\
\hline$(\mathrm{DE})_{4}$-Luc + Mixer & & + & 3.1 & 0.2 & 3.8 & 1.4 \\
\hline $\begin{array}{l}(\mathrm{ARE})_{3}-\mathrm{Luc} \\
\text { FoxH1a }\end{array}$ & + & + & 2.7 & 0.6 & 2.3 & 1.3 \\
\hline $\begin{array}{l}(\mathrm{ARE})_{3} \text {-Luc } \\
\text { FoxH1b }\end{array}$ & + & + & 4.5 & 0.9 & 2.8 & \\
\hline $\mathrm{CAGA}_{12}-\operatorname{Luc}(\mathrm{n}=2)$ & & + & 12.3 & 1.0 & 10.1 & 1.0 \\
\hline
\end{tabular}

Average TGF- $\beta$-induced transcriptional activation of the $(\mathrm{DE})_{4^{-}},(\mathrm{ARE})_{3^{-}}$and $\mathrm{CAGA}_{12}$-luciferase reporters in wild-type and $\mathrm{S} 2 \mathrm{KO}$ MEFs. In all instances $n=4$, except for $\mathrm{CAGA}_{12}$-Luc where $\mathrm{n}=2$. 


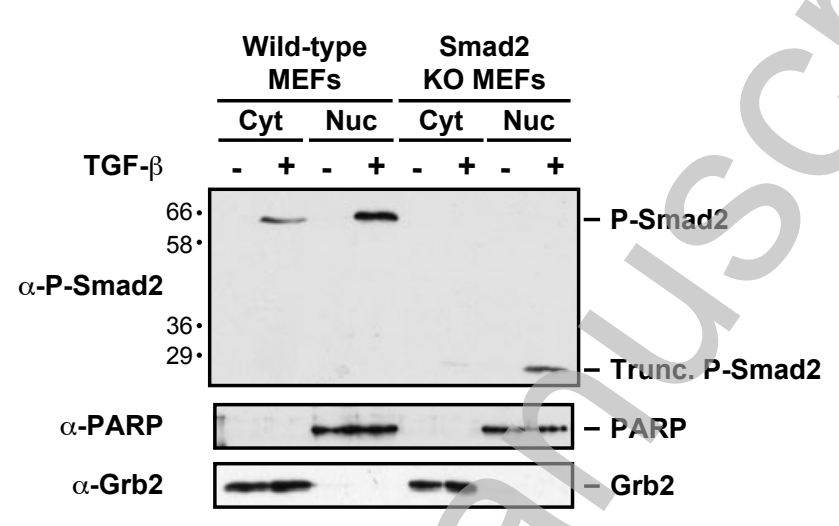

Figure 1

Licenced copy. Copying is not permitted, except with prior permission and as allowed by law. (C) 2008 The Authors Journal compilation (C) 2008 Biochemical Society 
A

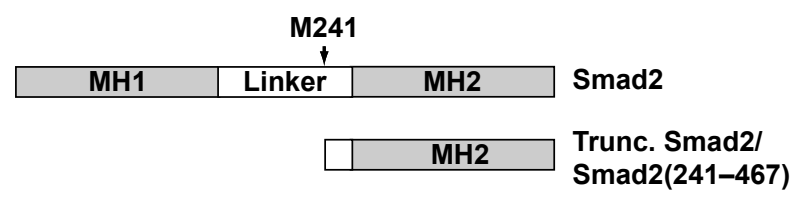

B

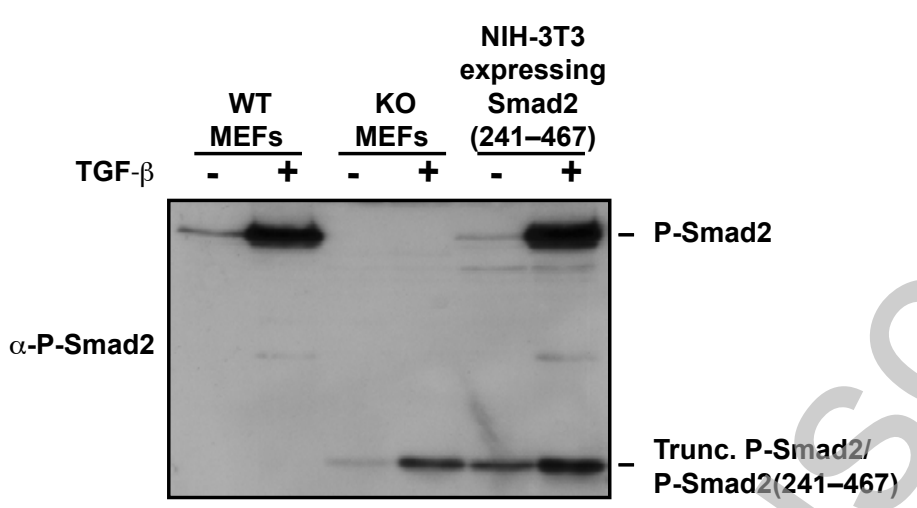

C
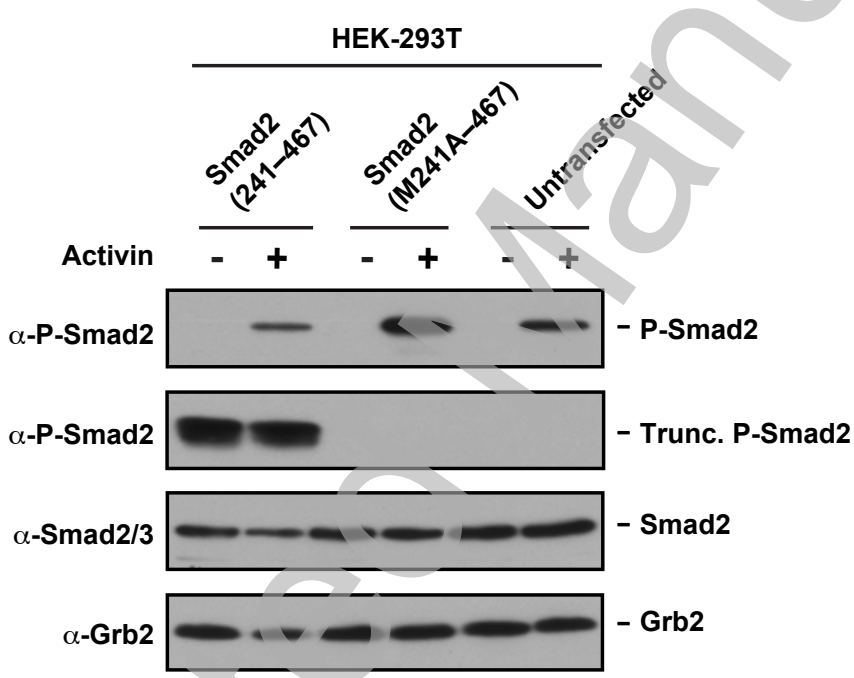

D

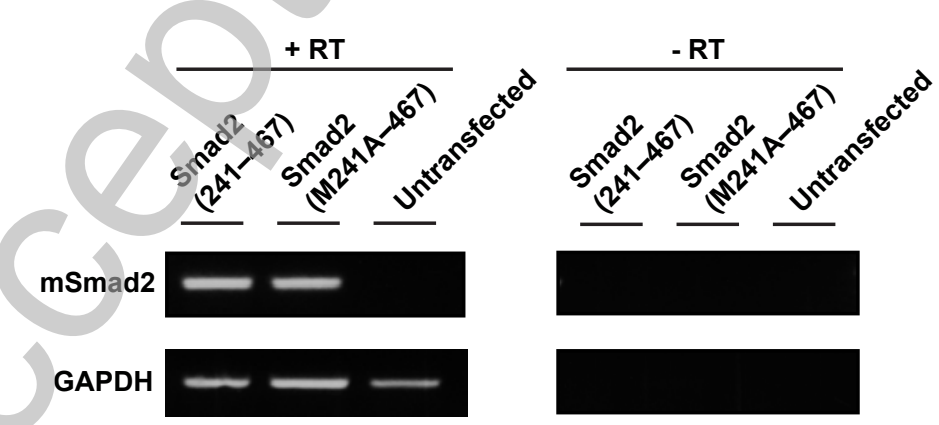

Licenced copy. Copying is not permitted, except with prior permission and as allowed by law. 
Figure 3 
A
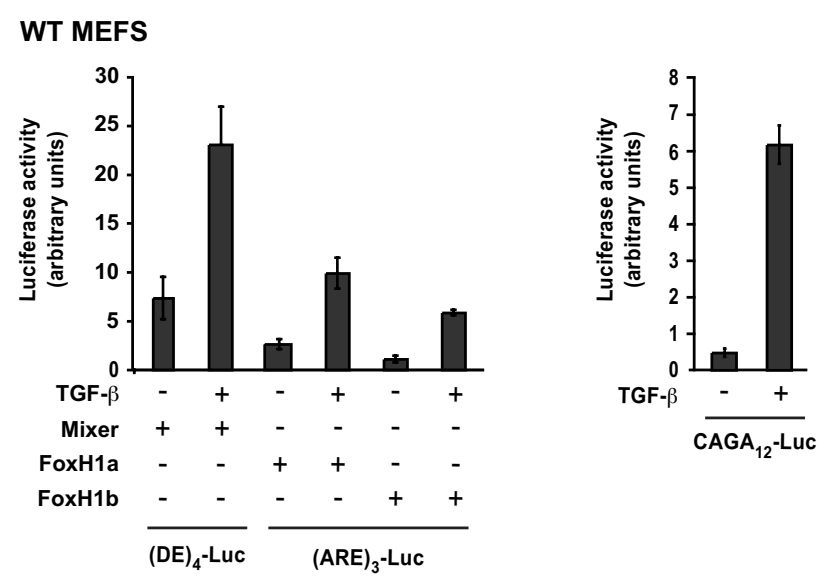

Smad2 KO MEFS
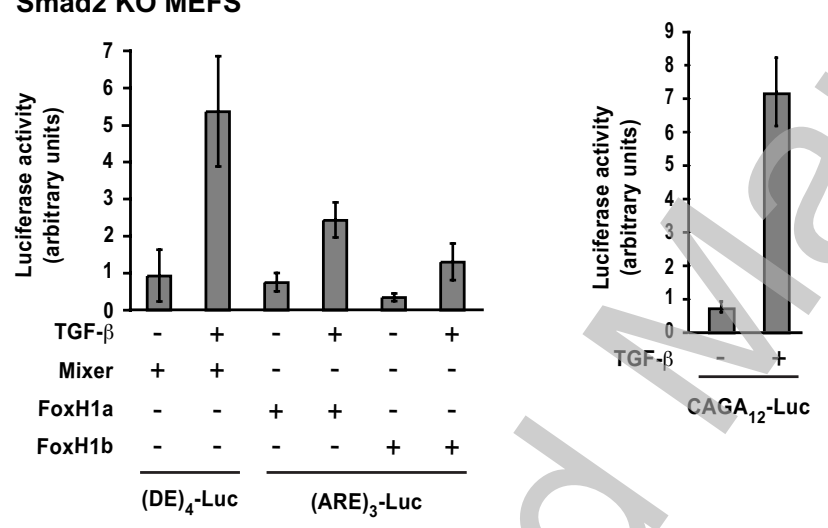

B

Smad2 KO MEFs

C

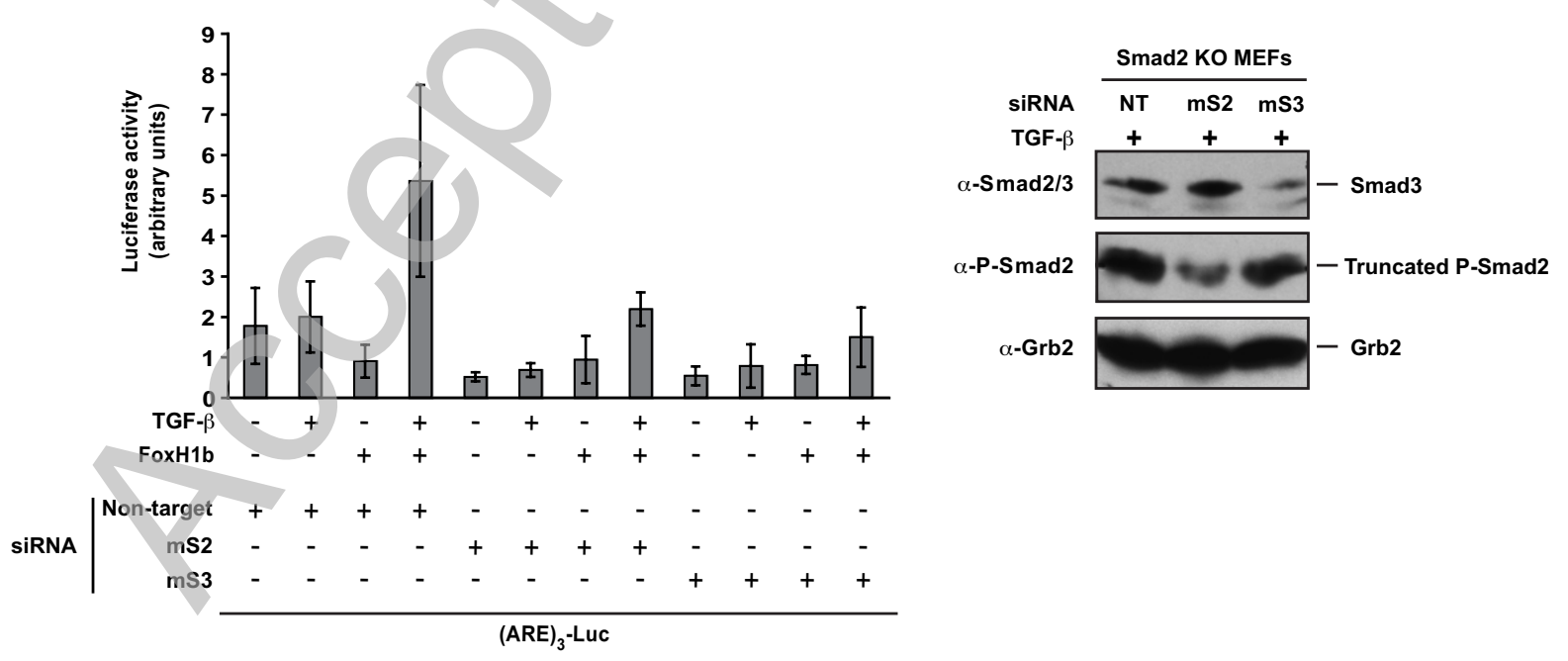

Figure 4

Licenced copy. Copying is not permitted, except with prior permission and as allowed by law. (C) 2008 The Authors Journal compilation (C) 2008 Biochemical Society 
A
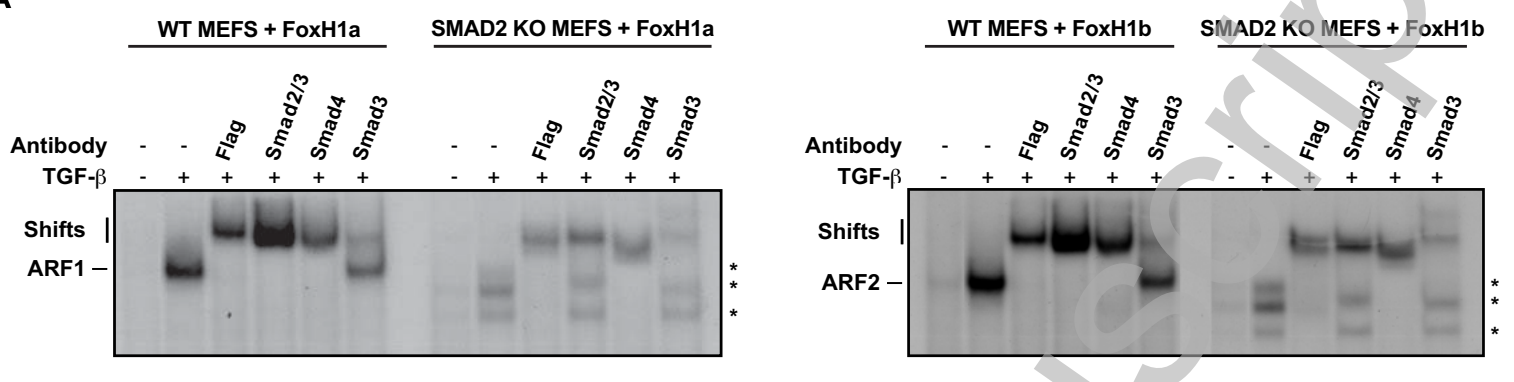

B

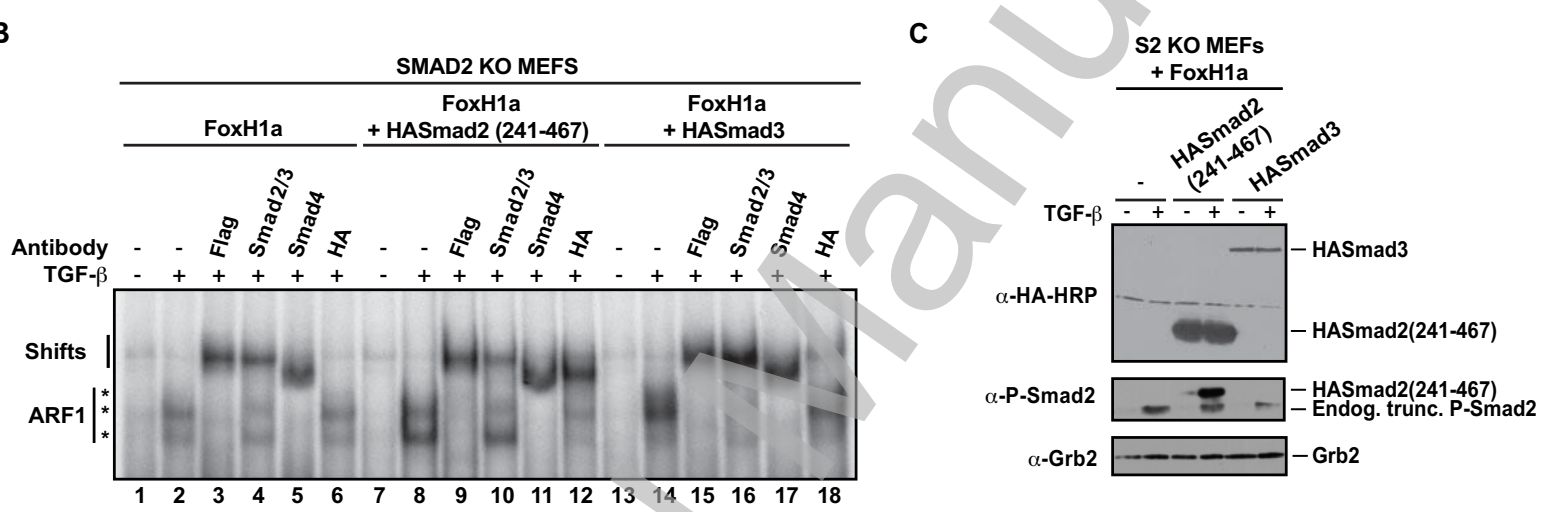

Figure 5

Licenced copy. Copying is not permitted, except with prior permission and as allowed by law. (C) 2008 The Authors Journal compilation (C) 2008 Biochemical Society 